\title{
Fulfilment of knowledge expectations and emotional state among people undergoing hip replacement: A multi-national survey
}

\author{
Åsa Johansson Stark, Brynja Ingadottir, Sanna Salanterä, Arun K Sigurdardottir, Kirsi \\ Valkeapää, Margareta Bachrach-Lindström and Mitra Unosson
}

\section{Linköping University Post Print}

\section{Tweet}

N.B.: When citing this work, cite the original article.

Original Publication:

Åsa Johansson Stark, Brynja Ingadottir, Sanna Salanterä, Arun K Sigurdardottir, Kirsi Valkeapää, Margareta Bachrach-Lindström and Mitra Unosson, Fulfilment of knowledge expectations and emotional state among people undergoing hip replacement: A multi-national survey, 2014, International Journal of Nursing Studies, (51), 11, 1491-1499.

http://dx.doi.org/10.1016/j.ijnurstu.2014.03.006

Copyright: Elsevier

http://www.elsevier.com/

Postprint available at: Linköping University Electronic Press

http://urn.kb.se/resolve?urn=urn:nbn:se:liu:diva-109769 
Fulfilment of knowledge expectations and emotional state among people undergoing hip replacement: A multi-national survey

- Åsa Johansson Stark, RNT, PhD-student, Department of Social and Welfare Studies, Faculty of Health Sciences, Linköping University, Sweden

- Brynja Ingadottir, RN, PhD-student, Department of Social and Welfare Studies, Faculty of Health Sciences, Linköping University, Sweden and Landspitali University Hospital, Iceland.

- Sanna Salanterä, RN, Professor, University of Turku, Department of Nursing Science, Head nurse, Turku University Hospital, Turku Finland

- Arun Sigurdardottir, RN, PhD, Professor, School of Health Sciences, University of Akureyri, Iceland

- Kirsi Valkeapää, RN, PhD, Adjunct Professor, University of Turku, Department of nursing Studies, Turku Finland and Dean Lahti University of Applied Sciences, Lahti Finland

- Margareta Bachrach-Lindström, RN, PhD, assistant professor, Department of Medical and Health Sciences, Faculty of Health Sciences, Linköping University, Sweden

- Mitra Unosson, RN, Professor emerita, Department of Social and Welfare Studies, Faculty of Health Sciences, Linköping University, Sweden

Correspondence: Åsa Johansson Stark asa.johansson.stark@liu.se Phone: +46 (0)11 363510

\section{Acknowledgements}

The authors acknowledge Elisabeth Wilhelm, Department of Medical and Health Sciences, Linköping University, and Jouko Katajisto, Department of Statistics, University of Turku, for statistical support. 


\begin{abstract}
Background: Patient education in connection with hip replacement is intended to prepare patients for surgery, discharge and postoperative recovery. Patients experience symptoms and emotions due to disease or upcoming surgery which can affect how their knowledge expectations are fulfilled.
\end{abstract}

Objectives: To describe the differences between received and expected knowledge in patients undergoing elective hip replacement in three Nordic countries, and to analyse how these differences are related to patients' characteristics, preoperative symptoms and emotions.

Design: A descriptive, prospective survey with two data collection points; before admission and at hospital discharge after surgery.

Settings: Two Finnish, three Icelandic and two Swedish hospitals.

Participants: The population consisted of patients on a waiting list for hip replacement. Of the consecutively included patients, 320 answered questionnaires both before admission and at discharge and were included in the study. The mean age of the patients was 64 years, and $55 \%$ were women.

Methods: Structured questionnaires were used; the Knowledge Expectations of hospital patients scale and self-reported scales for symptoms and emotions before admission and Received Knowledge of hospital patients scale at discharge. Fulfilment of knowledge expectation was assessed by calculating the difference between received and expected knowledge with a paired sample t-test. A multiple stepwise regression model was used to explain the variance of fulfilled knowledge expectations.

Results: Patients expected more knowledge than they received $(p<0.001)$ and $77 \%$ of them had unfulfilled knowledge expectations. Patients with a higher level of education were more 
likely to have unfulfilled knowledge expectations. A higher level of education was also related to a greater difference between received and expected knowledge. The difference was more correlated with patients' emotions than their symptoms. A depressive state was the major predictor of the variance in the difference between received and expected knowledge.

Conclusions: In order to better support patients by education it is necessary to assess their emotional state, educational level and knowledge expectations before surgery.

Keywords: Emotions, Empowering knowledge, Hip replacement, Knowledge expectations, Orthopaedic Nursing, Patient education, Symptoms

\section{What is already known about the topic?}

- Education benefits patients but the educational practices in hospital care need to be further developed.

- Patients have unfulfilled knowledge expectations.

\section{What this paper adds?}

- Seventy-seven percent of the patients undergoing hip replacement have unfulfilled knowledge expectations

- To a greater extent than other patients, patients in a depressive state receive less knowledge than they expect.

- The knowledge expectations of patients with a higher level of education are less fulfilled than those of patients with a lower level of education. 


\section{Background}

There is limited knowledge about whether patients undergoing elective hip replacement have their knowledge expectations fulfilled during a hospital stay. To support patients' empowerment through education there is therefore a need to be aware of these expectations and the factors that influence them.

Hip replacement is an effective and common treatment for people with osteoarthritis and has become a high volume surgery throughout Europe (Learmonth et al., 2007, Rasanen et al., 2007). The annual incidences in Finland, Iceland and Sweden are similar (Lohmander et al., 2006). During 2011 the incidence rates in these three countries were between 173238/100,000 inhabitants, which were above the average for the OECD countries (OECD, 2013).

Nordic co-operation has strong traditions in politics, economy and culture. The health care systems are public and have well-developed hospital services (Nordic Statistical Yearbook, 2011). This was also verified in the Euro Health Consumer Index which ranked the health care systems in Finland, Iceland and Sweden among the top ten of 34 European countries (Björnberg, 2012).

The number of hip replacements performed is increasing, and there is a higher incidence rate, 160 per 100,000 inhabitants, compared with knee replacement $(119 / 100,000)$ in the OECD countries (OECD 2013). Patients undergoing hip or knee replacement are often included in the same study although studies have reported differences in postoperative function (Choi et al., 2012, Ethgen et al., 2004, Wylde et al., 2009), self-perceived recovery and distress (Caracciolo and Giaquinto, 2005). Patients undergoing different kinds of arthroplasty may also have different knowledge expectations. In order to fulfil individual knowledge expectations of patient's undergoing elective hip replacement it is therefore important to 
identify the factors which make it unlikely for these patients to have their knowledge expectations fulfilled.

The length of hospital stay for patients undergoing hip replacement has decreased (Gulotta et al., 2011, Husted et al., 2010) which has put greater demands on perioperative practice, including patient education. This can be a challenge for the patients and it is therefore important to take their own resources, e.g. existing knowledge, into account when planning patient education (Johansson et al., 2005). Earlier studies have shown that patient education results in better preparation for surgery, better pain control (Kearney et al., 2011) and a shorter hospital stay (Yoon et al., 2010). It also reduces patients' anxiety and increases their knowledge level (Johansson et al., 2005).

Patients' rights to education and information are statutory in Finland (Act 785/1992), Iceland (Act 74/1997) and Sweden (Act 1982:763). In many countries, including the Nordic countries, education is provided to prepare patients for surgery, discharge and postoperative recovery but it still needs to be further developed (Blondal et al., 2011, Friberg et al., 2012), especially in hospital care (Bergh et al., 2012). With more fast track treatment followed by early discharge it is vital to improve patient education. This requires international studies, and including patients from Finland, Iceland and Sweden, which have similar health care systems, may generate knowledge that can support theory development and clinical practice of patient education.

Empowering patient education emphasizes the power of patients and their self-care as a goal of the education and is a relevant subject to study since patients need to be responsible for their own recovery (Johansson et al., 2005). Empowering patient education can take place when health care providers support patients in finding, constructing and using their own resources (Leino-Kilpi, 2009). Empowering knowledge is based on a model that has six 
dimensions: bio-physiological, functional, experiential, social, ethical and financial (LeinoKilpi et al., 2005, Rankinen et al., 2007). These aspects are important, as patients need to be prepared for both the surgical procedure as well as their recovery (Heikkinen et al., 2007). Patients that have their knowledge expectations fulfilled will have the opportunity to become empowered during the whole process, from preparation to recovery (Kuokkanen and LeinoKilpi, 2000, Suhonen and Leino-Kilpi, 2006) and will therefore improve their self-care (WHO, 2012). This assumption is based on theories that focus on individuals' own cognitive processing and use of knowledge (Kuokkanen and Leino-Kilpi, 2000, Thomas and Velthouse, 1990). To be able to support patients' empowerment by education it is therefore necessary to be aware of patients' knowledge expectations and the factors that influence them.

Studies on the difference between received and expected knowledge, i.e. fulfilled and unfulfilled knowledge expectations, show that patients have unfulfilled knowledge expectations in all dimensions of empowering knowledge (Rankinen et al., 2007, Ryhänen et al., 2012). Unfulfilled knowledge expectations are associated with being female, younger or having a higher level of basic education (Rankinen et al., 2007). Not only patients' characteristics but also their symptoms and emotions may affect the extent to which their knowledge expectations are fulfilled. Patients have reported fear of the overall surgery outcome or of specific problems with surgery and rehabilitation, which explains why the specific content of patient education is important (Soever et al., 2010). On the other hand, a study has shown that patient education did not affect patients' emotional state during the orthopaedic surgical process (Heikkinen et al., 2012). No studies have been found describing how differences between received and expected knowledge are related to patient's symptoms and emotions.

The aim of this study was to describe the differences between received and expected knowledge in patients undergoing elective hip replacement in three Nordic countries, and to 
analyse how these differences are related to patients' characteristics, preoperative symptoms and emotions.

\section{Method}

\subsection{Design}

This survey is a prospective study with data collected by questionnaires before hospital admission and at discharge after hip replacement. It is a part of a European project on empowering patient education for osteoarthritis patients undergoing hip or knee replacement (EEPO, 2009, Valkeapää et al., 2013).

\subsection{Sample and settings}

The study population consisted of patients with osteoarthritis on a waiting list for elective hip replacement at two Finnish, three Icelandic and two Swedish hospitals. The hospitals were non-randomly selected except for Iceland where all hospitals performing arthroplasty were included. Two of the included institutions were university hospitals and the others were community hospitals. The inclusion criteria for the patients were: age $\geq 18$ years and being able to complete the questionnaires. The sample resulted in 446 consecutively included patients of which $320(72 \%)$ answered questionnaires both before admission and at discharge, and the results of these questionnaires will be reported in this paper (Fig 1).

Figure 1 Flow chart of participant recruitment.

\subsection{Measurements}


The structured instruments Knowledge Expectations of hospital patients ( $\left.\mathrm{KE}_{\mathrm{hp}}\right)$ and Received Knowledge of hospital patients (RKhp) (Leino-Kilpi et al., 2005, Rankinen et al., 2007) are two 40-item scales with parallel questions which measure what empowering knowledge patients expect to get, and what they perceive they have actually received. Empowering knowledge is defined as six dimensional: bio-physiological (eight items e.g. knowledge about illness, symptoms, treatment, complications), functional (eight items e.g. mobility, rest, nutrition, bodily functions), experiential (three items e.g. emotions, hospital experiences), ethical (nine items e.g. rights, duties, participating in decision-making, confidentiality), social (six items e.g. support from family or community, social contact, patient organizations) and financial (six items e.g. costs, financial benefits). Response options for each item were categorized from $1=$ fully disagree to $4=$ fully agree and $0=$ not applicable. The scores for each dimension and the total scale are the mean values of included items, with a possible range of 1-4. When calculating these means the response option 'not applicable' was excluded. High scores indicate high knowledge expectations or a high level of received knowledge. $\mathrm{KE}_{\mathrm{hp}}$ and $\mathrm{RK}_{\mathrm{hp}}$ were found to have good content validity (Heikkinen et al., 2007, Leino-Kilpi et al., 2005) and internal consistency with a Cronbach's alpha ranging between 0.87 to 0.94 (Rankinen et al., 2007, Valkeapaa et al., 2013). In the present study the Cronbach's alphas for the total scale of $\mathrm{KE}_{\mathrm{hp}}$ and $\mathrm{RK}_{\mathrm{hp}}$ were 0.97 , the dimensions ranged from 0.87 to 0.92 for the $\mathrm{KE}_{\mathrm{hp}}$ scale, and from 0.83 to 0.95 for the $\mathrm{RK}_{\mathrm{hp}}$ scale.

Self-reported scales were administered to assess the prevalence and frequency of symptoms (eight items) and emotions (nine items) (Heikkinen et al., 2012). Response options for each item ranged from $1=$ not at all to $4=$ very often.

Patients' characteristics were collected on age, sex, present employment status, earlier employment in social or healthcare, and whether patients were undergoing their first joint replacement or not. Educational levels were identified; basic education and different levels of 
vocational training after basic education were defined as professional education. Patients were also asked two questions about the length of their present hospital stay and if it had been as expected.

The translation procedure, including back-translation, of instruments and questionnaires was performed. The questionnaires were piloted in each country in a corresponding group of 30 patients per country (Figure 1) and were found to be understandable and easy to complete.

\subsection{Procedures}

Data was collected between 2009 and 2011. Staff nurses at the participating hospitals sent written information about the study to each patient's home within a month before admission to hospital. The information covered informed consent, the $\mathrm{KE}_{\mathrm{hp}}$ scale, and self-reported scales for symptoms and emotions. Patients sent the completed questionnaires by prepaid envelope to a member of the research group or returned it during a preoperative meeting prior to surgery and prior to formal preoperative education. After surgery and before discharge, the $\mathrm{RK}_{\mathrm{hp}}$ scale was distributed to all included patients and they returned these to mailboxes placed on the wards or sent them back by prepaid envelope to a member of the research group.

The hospitals' standardised educational practices were used, including providing written information about the hospital stay.

\subsection{Ethical considerations}

All relevant permissions and ethical approval were obtained and good ethical research praxis based on the Helsinki Declaration was followed (WMA, 1964). Patients were informed of the purpose of the study, about the principles of voluntary participation and confidentiality, and they gave written informed consent. 


\subsection{Data analysis}

Descriptive statistics were used to describe the sample characteristics. Differences between groups were calculated with Chi-2 for nominal data, Kruskal-Wallis for ordinal data and OneWay ANOVA for continuous data. For statistically significant analysis, further tests were done; Kruskal-Wallis was followed by post hoc Mann-Whitney test, and the ANOVA was followed by post hoc Students $t$-test with Bonferroni correction (Polit and Beck, 2012).

Differences between perceptions of received knowledge and knowledge expectations were calculated with a paired sample t-test $\left(\mathrm{RK}_{\mathrm{hp}}-\mathrm{KE}_{\mathrm{hp}}\right)$. The distribution of this difference was tested by Kolmogorov-Smirnov. If the difference was negative the patients had higher expectations than received knowledge, and were defined as having unfulfilled knowledge expectations. Patients with no or a positive difference were defined as experiencing fulfilled expectations. Differences between patients with unfulfilled and fulfilled knowledge expectations were calculated using a chi-2 or t-test for independent samples when appropriate.

The associations of the 'difference between received and expected knowledge' with patients' characteristics was tested by one-way ANOVA (country, professional education), by Student's t-test (hospital stay as expected), or by Pearson's correlation coefficient (length of hospital stay). Spearman's correlation coefficient was used to analyse the relationship between the differences in received and expected knowledge for each symptom and emotion.

The calculated difference between received and expected knowledge was entered into a multiple stepwise regression model as a dependent variable. Independent variables were symptoms and emotions with a prevalence of $\geq 50 \%$ and significant correlations with this difference (pain, tiredness or fatigue, sleeplessness, sense of weakness, concern, impatience, uncertainty, fear, anxiety, depressive state), together with variables associated with the 
difference between received and expected knowledge (country, professional education) and sex.

Internal missing data ranged between $0-13 \%$, and imputation was not carried out. The level of statistical significance was set at $p<0.05$. Data were analysed using $\operatorname{SPSS}^{\circledR}$ version 20.

\section{Results}

\subsection{Characteristics of the sample}

There were no significant differences between the 320 respondents and the 125 nonresponders at hospital discharge in any of the patient's characteristics presented in table 1, ( $p>0.05$ ) or knowledge expectations ( $p=0.92$ for the total scale). Of the 320 included patients, 177 (55\%) were women (table 1). The mean age was 64 ( \pm SD 11) years. For $76 \%$ of the patients this was their first arthroplasty. Half of the patients had no professional education or a secondary level, and $43 \%$ had college or academic level education. When comparing the countries, Swedish patients had a higher level of both basic and professional education compared with Finland and Iceland ( $p<0.01$ and $<0.05$ respectively). A majority $(91 \%)$ of the patients evaluated the hospital stay as meeting expectations. No significant differences were found between patients with unfulfilled or fulfilled knowledge expectations for length of hospital stay.

\section{Table 1, here}

\subsection{The difference between received and expected knowledge}

Of the 320 patients, 247 (77\%) had unfulfilled and 73 (23\%) had fulfilled knowledge expectations (table 1). More Swedish patients had unfulfilled knowledge expectations than 
Finnish and Icelandic patients $(p<0.01)$. The level of basic education was related to whether patients' knowledge expectations were fulfilled or not $(p<0.05)$. Of patients with fulfilled expectations, 54\% had the lowest level of basic education (primary school).

Patients perceived that they received less knowledge than they had expected in all dimensions and for the total scale of empowering knowledge (Table 2). The difference between received and expected knowledge of the total scale was normally distributed (Kolmogorov-Smirnov $p=.639$ ) with a range between -2.95 to 2.27 . The smallest mean difference was in the biophysiological and functional dimensions -0.3 (SD 0.6) and greatest in the financial dimension, -1.3 (SD 0.8). The proportions of patients with unfulfilled knowledge expectations ranged between 55\% (bio-physiological dimension) and $81 \%$ (financial dimension).

Table 2, here

\subsection{The difference between received and expected knowledge related to patients'} characteristics

The difference between received and expected knowledge for the total scale was related to country, professional education and whether the hospital stay was as expected. This difference was larger in Sweden -0.9 (SD 0.7) compared with Finland -0.4 (SD 0.8) and Iceland -0.5 (SD 0.6) $(p<0.001)$. Patients with professional education on an academic level showed a greater difference between received and expected knowledge - 0.9 (SD 0.8) than patients with no professional education -0.5 (SD 0.7), education on a secondary level -0.5 (SD 0.7) or college level -0.6 (0.9) $(p<0.05)$. Patients who experienced the hospital stay as meeting expectations showed a smaller difference between received and expected knowledge, $-0.5(0.7)$ than those who did not $-1.0(0.9)(\mathrm{p}<0.001)$. No correlation was found between length of hospital stay and the difference between received and expected knowledge, $r_{p} .029(p>0.05)$. 


\subsection{Symptoms and emotions before hospital admission, and their relationship to the difference between received and expected knowledge}

The most common symptoms patients experienced before admission to hospital were pain, 'tiredness or fatigue', sleeplessness and a sense of weakness with a prevalence between 77$100 \%$ (table 3$)$. The least common symptom was 'nausea or vomiting' $(19 \%)$. The most common emotions before admission were hope, concern, impatience and uncertainty (73$96 \%$ ) and the least common were grief and despair or hopelessness (44-45\%). The prevalence for depressive state was $55 \%$ in the total sample. The proportion of patients with depressive state in each country was 31 (35\%) for Finland, 42 (45\%) for Iceland and 97 (78\%) for Sweden.

The differences between received and expected knowledge of the total scale correlated significantly with the frequency of the following symptoms; pain, 'tiredness or fatigue', sleeplessness and sense of weakness and the emotions; concern, impatience, uncertainty, fear, anxiety, depressive state, 'despair or hopelessness' and grief before admission to hospital (table 3).

\subsection{Predictors explaining the difference between received and expected knowledge}

Multiple regression analysis showed that the predictor variables explained $22.1 \%$ of the variance in the difference between received and expected knowledge (table 4). Depressive state was the major predictor and could explain $16.2 \%$ (adjusted $R^{2}$ ) of the variance. The difference between received and expected knowledge was greater when patients reported a higher occurrence of depressive state and anxiety, and for patients with higher professional 
education. The Swedish patients showed a greater difference between received and expected knowledge than the Finnish and Icelandic patients.

\section{Table 4 here}

\section{Discussion}

In this study, negative emotions such as fear, depressive state, concern and anxiety were related to unfulfilled knowledge expectations, and depressive state was the major predictor of the variance in the difference between received and expected knowledge. Patients' knowledge expectations were most fulfilled in the bio-physiological dimension which includes items about symptoms related to the illness but less fulfilled in the experiential dimension including items about their emotions. Therefore, patient education should address how the illness and its treatment could affect patients emotionally, and who the patient can talk with about these. In addition, assessment of patients' emotional state before surgery would help nurses to identify those at risk of having their knowledge expectations unfulfilled. In qualitative studies exploring experiences of orthopaedic surgery, patients' emotions such as hope, fear, feeling safe and loss of independence seem to be more important than their symptoms (Gustafsson et al., 2010, Heine et al., 2004, Perry et al., 2012).

Level of education seems to be an important factor as patients with higher basic education had more unfulfilled knowledge expectations, and patients with higher professional education showed a larger difference between received and expected knowledge. Professional education could also predict some of the variance of the difference between received and expected knowledge. This was also verified in a study on surgical patients which found that patients with a higher level of basic education showed a larger difference between received and expected knowledge (Rankinen et al., 2007). In contrast, in a study in our European project on 
patients undergoing knee replacement, no such difference was found for level of professional education (Ingadottir et al., 2014). However, it has also been found that when patient education increases, patients' knowledge expectations increase as well while their perceptions of received knowledge decrease (Ryhänen et al., 2012). More patient education or a higher level of education seems to be associated with more unfulfilled knowledge expectations. Patient education therefore needs to be customised to meet patients' level of education and their knowledge expectations.

Swedish patients had a higher level of professional education compared with the Finnish and Icelandic patients. The proportion of patients having a depressive state was also highest in Sweden. These factors may explain why Swedish patients showed a greater difference between received and expected knowledge and had more unfulfilled knowledge expectations than Finnish and Icelandic patients.

Patients' knowledge expectations were highest in the bio-physiological and functional dimension and those were also the best fulfilled, as in earlier studies (Heikkinen et al., 2007, Montin et al., 2010, Valkeapaa et al., 2013). Consistent with earlier research (Ingadottir et al., 2014, Rankinen et al., 2007, Ryhanen et al., 2012) our results showed that patients undergoing hip replacement also had unfulfilled knowledge expectations in all dimensions of empowering knowledge. It seems that patient education about bio-physiological and functional aspects is prioritised. Therefore, it is important to raise the awareness of patients' need for education from the other dimensions. An interesting question for further research is how large the difference between received and expected knowledge has to be in order to be considered clinical relevant.

In this study, $91 \%$ of the patients found the hospital stay to be as they had expected, and this factor was related to a smaller difference between received and expected knowledge. The 
same result was shown in a study on patients undergoing knee replacement (Ingadottir et al., 2014). These results indicate that patients who had their knowledge expectations fulfilled also found the hospital stay to be as expected. It seems that fulfilled knowledge expectations and general expectations of the hospital stay are related to each other. This may strengthen the main assumption for empowering patient education; patients that have their knowledge expectations met have a greater possibility for empowerment and thus for self-care.

This study focused on whether patient's knowledge expectations are being fulfilled. Patients have their own individual expectations of patient education and a positive correlation between individualised care and patient satisfaction has been found (Suhonen et al., 2012). Personcentred care has recently been defined as a holistic approach to delivering care that is respectful and individualised, allowing negotiation of care, and offering choice through a therapeutic relationship where persons are empowered to be involved in health decisions at whatever level is desired by the individual who is receiving the care (Morgan and Yoder, 2012). Three routines are proposed to facilitate a person-centred approach to care; first establishing a partnership by asking for the patients' narrative; second, shared decisionmaking build on the partnership; and third, the documentation of the patient's narrative in the patient record to empower the value of the partnership (Ekman et al., 2011). Nurses have an important role in patient education (Nolan et al., 2001). By choosing person-centred care as a guiding model in nursing practice an individualised education, where the patient is empowered to be involved and have his/her desired knowledge expectations fulfilled, can be achieved.

In our study no relation was found between the length of hospital stay and whether patients had their knowledge expectations fulfilled or not. Therefore, we cannot state that a shorter hospital stay means fewer knowledge expectations fulfilled. Earlier studies have contradictory results; preoperative education was found to reduce length of hospital stay (Yoon et al., 2010) 
but also to have no effect on hospital stay (Sjöling, 2003, Vukomanovic et al., 2008). We did not study the existing patient educational routines and therefore cannot state if they are adequate or not. It is possible that patients expect or need improved patient education before admission to hospital, during the hospital stay, and after discharge when the hospital stay is shorter. Further studies are needed to gain new knowledge within this area.

One of the strengths of the study is the large sample size. The non-random choice of hospitals means that the results may not be generalised to more than participating hospitals except for Iceland, where all hospitals performing arthroplasty were included. The instruments, $\mathrm{KE}_{\mathrm{hp}}$, $\mathrm{RK}_{\mathrm{hp}}$ and the self-reported scales for symptoms and emotions have been developed and used in Finland, and content validity and reliability has been tested in a Finnish context (Heikkinen et al., 2012, Leino-Kilpi et al., 1998, Leino-Kilpi et al., 1999). Even though the Nordic countries have a similar cultural context and comparable health care, there may have been some difficulties in the translation and cultural validation (Cha et al., 2007). There might for example have been different perceptions about what a depressive state means in the different languages. It may be difficult to compare different levels of education between the Nordic countries (Nordic statistical yearbook 2011). In addition, the educational systems in each country have changed over time, including the length of time spent at each level. However, the educational systems are similar and have developed in coordination in the Nordic countries. Low internal missing data and the result of the pilot study indicated that patients found the questionnaires relevant and easy to understand. The reliability for the $\mathrm{KE}_{\mathrm{hp}}$ and $\mathrm{RK}_{\mathrm{hp}}$ scales, tested by Cronbach’s alphas, indicated good consistency (Beckstead, 2013, Tavakol and Dennick, 2011). Despite this support for the reliability, further validation of the instruments is needed both in the Nordic and European contexts.

\section{Conclusion}


The conclusions from this study emphasize the importance of identifying anxious patients, patients in a depressive state, and also those with a higher level of education, and then focusing on fulfilling their knowledge expectations. The most important implication is that nurses should identify patients undergoing elective hip replacement who are at risk of having unfulfilled knowledge expectations. In addition support them in fulfilling their individual knowledge expectations in all dimensions of empowering knowledge by implementing person-centred care in nursing practice. The challenge may be to change focus from "doing for" the patient to "doing with" the patient.

\section{Ethical approval}

Ethical approvals in participating countries were obtained; Finland ETMK 102/180/2008, Iceland 09-084-SI, Sweden Dnr. M69-0.

\section{Funding}

This study was financially supported by: The University of Turku; The Academy of Finland; The Finnish Association of Nursing Research; The Finnish Foundation of Nursing Education. The Landspitali Science Fund; The Akureyri Hospital Science Fund; The University of Akureyri Science Fund; the KEA fund, Akureyri; The Icelandic Nurses' Association Science Fund; The Swedish Rheumatism Association and the County Council of Östergötland and Linköping University.

\section{Conflict of interest}

There are no conflicts of interest to declare. 


\section{References}

Act 785/1992. About Patients' Rights. (Finland) URL: http://www.finlex.fi/en/laki/kaannokset/1992/en19920785.pdf

Act 74/1997. Act on Patients' Rights. (Iceland) URL: http://www.althingi.is/lagas/138b/1997074.html

Act 1982:763. Health and Medical Services (Sweden) URL: http://www.notisum.se/rnp/sls/lag/19820763.HTM

Beckstead, J.W., 2013. On measurements and their quality: Paper 1: Reliability - History, issues and procedures. International journal of nursing studies 50 (7), 968-973.

Bergh, A.L., Karlsson, J., Persson, E., Friberg, F., 2012. Registered nurses' perceptions of conditions for patient education - focusing on organisational, environmental and professional cooperation aspects. Journal of nursing management 20 (6), 758-770.

Björnberg, A., 2012. Euro Health Consumer Index 2012 (EHCI): the 6th edition of the Euro Health Consumer Index 2012. Health Consumer Powerhouse.

Blondal, K., Olafsdottir, H. S., Johannesdottir, S., Sveinsdottir, H., 2011. Surgery related information: content, satisfaction and influential factors. The Icelandic Journal of Nursing 87 (1), 49-60.

Caracciolo, B., Giaquinto, S., 2005. Self-perceived distress and self-perceived functional recovery after recent total hip and knee arthroplasty. Archives of Gerontology and Geriatrics 41 (2), 177-181.

Cha, E.S., Kim, K.H., Erlen, J.A., 2007. Translation of scales in cross-cultural research: issues and techniques. Journal of Advanced Nursing 58 (4), 386-395.

Choi, J.K., Geller, J.A., Yoon, R.S., Wang, W., Macaulay, W., 2012. Comparison of Total Hip and Knee Arthroplasty Cohorts and Short-Term Outcomes From a Single-Center Joint Registry. The Journal of Arthroplasty 27 (6), 837-841.

EEPO, 2009. Empowering Surgical Orthopaedic Ppatients Through Education. University of Turku, Department of Nursing Science, Turku. URL: http://www.med.utu.fi/hoitotiede/epe/research/post-doctoralstudies/eepo.html

Ekman, I., Swedberg, K., Taft, C., Lindseth, A., Norberg, A., Brink, E., Carlsson, J., Dahlin-Ivanoff, S., Johansson, I.L., Kjellgren, K., Liden, E., Ohlen, J., Olsson, L.E., Rosen, H., Rydmark, M., Sunnerhagen, K.S., 2011. Person-centered care--ready for prime time. European journal of cardiovascular nursing 10 (4), 248-251.

Ethgen, O., Bruyere, O., Richy, F., Dardennes, C., Reginster, J.Y., 2004. Health-related quality of life in total hip and total knee arthroplasty. A qualitative and systematic review of the literature. The Journal of bone and joint surgery. American volume 86-A (5), 963-974.

Friberg, F., Granum, V., Bergh, A.L., 2012. Nurses' patient-education work: conditional factors - an integrative review. Journal of nursing management 20 (2), 170-186.

Gulotta, L.V., Padgett, D.E., Sculco, T.P., Urban, M., Lyman, S., Nestor, B.J., 2011. Fast Track THR: One Hospital's Experience with a 2-Day Length of Stay Protocol for Total Hip Replacement. HSS journal : the musculoskeletal journal of Hospital for Special Surgery 7 (3), 223-228.

Gustafsson, B., Ekman, S., Ponzer, S., Heikkilä, K., 2010. The hip and knee replacement operation: an extensive life event. Scandinavian Journal of Caring Sciences 24 (4), 663-670.

Heikkinen, K., Leino-Kilpi, H., Hiltunen, A., Johansson, K., Kaljonen, A., Rankinen, S., Virtanen, H., Salantera, S., 2007. Ambulatory orthopaedic surgery patients' knowledge expectations and perceptions of received knowledge. Journal of advanced nursing 60 (3), 270-278.

Heikkinen, K., Salantera, S., Leppanen, T., Vahlberg, T., Leino-Kilpi, H., 2012. Ambulatory orthopaedic surgery patients' emotions when using different patient education methods. Journal of perioperative practice 22 (7), 226-231.

Heine, J., Koch, S., Goldie, P., 2004. Patients' experiences of readiness for discharge following a total hip replacement. The Australian journal of physiotherapy 50 (4), 227-233.

Husted, H., Hansen, H.C., Holm, G., Bach-Dal, C., Rud, K., Andersen, K.L., Kehlet, H., 2010. What determines length of stay after total hip and knee arthroplasty? A nationwide study in Denmark. Archives of Orthopaedic and Trauma Surgery 130 (2), 263-268.

Ingadottir, B., Johansson Stark, A., Leino-Kilpi, H., Sigurdardottir, A. K., Valkeapaa, K., \& Unosson, M. (2014). The fulfilment of knowledge expectations during the perioperative period of patients undergoing knee arthroplasty - a Nordic perspective. J Clin Nurs. doi: 10.1111/jocn.12552 
Johansson, K., Nuutila, L., Virtanen, H., Katajisto, J., Salantera, S., 2005. Preoperative education for orthopaedic patients: systematic review. Journal of Advanced Nursing 50 (2), 212-223.

Johansson, K., Nuutila, L., Virtanen, H., Katajisto, J., Salantera, S., 2005. Preoperative education for orthopaedic patients: systematic review. Journal of Advanced Nursing 50 (2), 212-223.

Kearney, M., Jennrich, M.K., Lyons, S., Robinson, R., Berger, B., 2011. Effects of Preoperative Education on Patient Outcomes After Joint Replacement Surgery. Orthopaedic Nursing 30 (6), 391-396.

Kuokkanen, L., Leino-Kilpi, H., 2000. Power and empowerment in nursing: three theoretical approaches. Journal of Advanced Nursing 31 (1), 235-241.

Learmonth, I.D., Young, C., Rorabeck, C., 2007. The operation of the century: total hip replacement. Lancet 370 (9597), 1508-1519.

Leino-Kilpi, H., 2009. Editorial Comment. Self-care and empowerment of individuals and populations. Nursing ethics 16 (3), 265-266.

Leino-Kilpi, H., Johansson, K., Heikkinen, K., Kaljonen, A., Virtanen, H., Salantera, S., 2005. Patient education and health-related quality of life: surgical hospital patients as a case in point. Journal of Nursing Care Quality 20 (4), 307-316; quiz 317-308.

Leino-Kilpi, H., Luoto, E., Katajisto, J., 1998. Elements of empowerment and MS patients. The Journal of neuroscience nursing : journal of the American Association of Neuroscience Nurses 30 (2), 116-123.

Leino-Kilpi, H., Maenpaa, I., Katajisto, J., 1999. Nursing study of the significance of reumatoid arthritis as perceived by patients using the concept of empowerment. Journal of Orthopaedic Nursing 3, 138-145.

Lohmander, L.S., Engesaeter, L.B., Herberts, P., Ingvarsson, T., Lucht, U., Puolakka, T.J., 2006. Standardized incidence rates of total hip replacement for primary hip osteoarthritis in the 5 Nordic countries: similarities and differences. Acta orthopaedica 77 (5), 733-740.

Montin, L., Johansson, K., Kettunen, J., Katajisto, J., Leino-Kilpi, H., 2010. Total joint arthroplasty patients' perception of received knowledge of care. Orthopaedic nursing 29 (4), 246-253.

Morgan, S., Yoder, L.H., 2012. A concept analysis of person-centered care. J Holist Nurs 30 (1), 6-15.

Nolan, J., Nolan, M., Booth, A., 2001. Developing the nurse's role in patient education: rehabilitation as a case example. International Journal of Nursing Studies 38 (2), 163-173.

Nordic Statistical Yearbook, 2011. Nordic Statistical Yearbook. In: Nord 2011:001.

OECD, 2013. "Hip and knee replacement" in Health at a Glance 2013: OECD Indicators. OECD Publishing.

Perry, M.A., Hudson, H.S., Meys, S., Norrie, O., Ralph, T., Warner, S., 2012. Older adults' experiences regarding discharge from hospital following orthopaedic intervention: A metasynthesis. Disability \& Rehabilitation 34 (4), 267-278.

Polit, D.F., Beck, C.T., 2012. Nursing research: generating and assessing evidence for nursing practice, Philadelphia: Wolters Kluwer Health/Lippincott Williams \& Wilkins, $9^{\text {th }}$ ed.

Rankinen, S., Salantera, S., Heikkinen, K., Johansson, K., Kaljonen, A., Virtanen, H., Leino-Kilpi, H., 2007. Expectations and received knowledge by surgical patients. International journal for quality in health care 19 (2), 113-119.

Rasanen, P., Paavolainen, P., Sintonen, H., Koivisto, A.M., Blom, M., Ryynanen, O.P., Roine, R.P., 2007. Effectiveness of hip or knee replacement surgery in terms of quality-adjusted life years and costs. Acta orthopaedica 78 (1), 108-115.

Ryhänen, A.M., Rankinen, S., Siekkinen, M., Saarinen, M., Korvenranta, H., Leino-Kilpi, H., 2012. The impact of an empowering Internet-based Breast Cancer Patient Pathway programme on breast cancer patients' knowledge: a randomised control trial. Patient Education and Counseling 88 (2), 224-231.

Sjoling, M., Nordahl, G., Olofsson, N., Asplund, K., 2003. The impact of preoperative information on state anxiety, postoperative pain and satisfaction with pain management. Patient Education and Counseling 51 (2), 169-176.

Soever, L.J., Mackay, C., Saryeddine, T., Davis, A.M., Flannery, J.F., Jaglal, S.B., Levy, C., Mahomed, N., 2010. Educational needs of patients undergoing total joint arthroplasty. Physiotherapy Canada. Physiotherapie Canada 62 (3), 206-214.

Suhonen, R., Leino-Kilpi, H., 2006. Adult surgical patients and the information provided to them by nurses: a literature review. Patient education and counseling 61 (1), 5-15. 
Suhonen, R., Papastavrou, E., Efstathiou, G., Tsangari, H., Jarosova, D., Leino-Kilpi, H., Patiraki, E., Karlou, C., Balogh, Z., Merkouris, A., 2012. Patient satisfaction as an outcome of individualised nursing care. Scandinavian Journal of Caring Sciences 26 (2), 372-380.

Tavakol, M., Dennick, R., 2011. Making sense of Cronbach's alpha. International Journal of Medical Education 2, 53-55.

Thomas, K.W., Velthouse, B.A., 1990. Cognitive Elements of Empowerment - an Interpretive Model of Intrinsic Task Motivation. Academy of Management Review 15 (4), 666-681.

Valkeapää, K., Klemetti, S., Cabrera, E., Cano, S., Charalambous, A., Copanitsanou, P., Ingadottir, B., Istomina, N., Johansson Stark, Å., Katajisto, J., Lemonidou, C., Papastavrou, E., Sigurdardottir, A.K., Sourtzi, P., Unosson, M., Zabalegui, A., Leino-Kilpi, H., 2013. Knowledge expectations of surgical orthopaedic patients: A European survey. International journal of nursing practice (Accepted 2013-04-15).

Vukomanovic, A., Popovic, Z., Durovic, A., Krstic, L., 2008. The effects of short-term preoperative physical therapy and education on early functional recovery of patients younger than 70 undergoing total hip arthroplasty. Vojnosanit Pregl 65 (4), 291-297.

WHO, 2012. Chronic diseases and health promotion: Chronic rheumatic conditions. World Health Organisation.

WMA, 1964. Declaration of Helsinki - Ethical Principles for Medical Research Involving Human Subjects. World Medical Association (WMA).

Wylde, V., Blom, A.W., Whitehouse, S.L., Taylor, A.H., Pattison, G.T., Bannister, G.C., 2009. Patient-Reported Outcomes After Total Hip and Knee Arthroplasty: Comparison of Midterm Results. The Journal of Arthroplasty 24 (2), 210-216.

Yoon, R.S., Nellans, K.W., Geller, J.A., Kim, A.D., Jacobs, M.R., Macaulay, W., 2010. Patient Education Before Hip or Knee Arthroplasty Lowers Length of Stay. Journal of Arthroplasty 25 (4), 547-551. 


\section{Table 1}

Sample characteristics and comparison between patients with unfulfilled and fulfilled knowledge expectations

\begin{tabular}{|c|c|c|c|c|}
\hline & $\begin{array}{c}\text { Total } \\
\text { sample } \\
n=320\end{array}$ & $\begin{array}{r}\text { Unfulfilled } \\
\text { expectations } \\
n=247\end{array}$ & $\begin{array}{r}\text { Fulfilled } \\
\text { expectations } \\
n=73\end{array}$ & $p<$ \\
\hline Countries n (\%) & & & & $<0.01^{\mathrm{a}}$ \\
\hline Finland & $97(30)$ & $69(28)$ & $28(38)$ & \\
\hline Iceland & $98(31)$ & $70(28)$ & $28(38)$ & \\
\hline Sweden & $125(39)$ & $108(44)$ & $17(23)$ & \\
\hline Age in years, mean $( \pm S D)$ & $64(11)$ & $64(12)$ & $66(11)$ & \\
\hline \multicolumn{5}{|l|}{$\operatorname{Sex} \mathrm{n}(\%)$} \\
\hline Female & $177(55)$ & $142(58)$ & $35(48)$ & \\
\hline Basic education $\mathrm{n}(\%)$ & & & & $<0.05^{\mathrm{a}}$ \\
\hline Primary school (or less) & $117(40)$ & $80(36)$ & $37(54)$ & \\
\hline Secondary/comprehensive school & $82(28)$ & $65(29)$ & $17(25)$ & \\
\hline Matriculation examination & $81(28)$ & $68(30)$ & $13(19)$ & \\
\hline Other & $12(4)$ & $11(5)$ & $1(1)$ & \\
\hline \multicolumn{5}{|l|}{ Professional education $\mathrm{n}(\%)$} \\
\hline None & $77(26)$ & $56(24)$ & $21(33)$ & \\
\hline Secondary level & $71(24)$ & $52(22)$ & $19(30)$ & \\
\hline College level & $74(25)$ & $59(26)$ & $15(23)$ & \\
\hline Academic level & $53(18)$ & $48(21)$ & $5(8)$ & \\
\hline Other & $20(7)$ & $16(7)$ & $4(6)$ & \\
\hline \multicolumn{5}{|l|}{ Employment status n (\%) } \\
\hline Employed & $146(46)$ & $119(49)$ & $27(38)$ & \\
\hline Retired & $154(49)$ & $112(46)$ & $42(58)$ & \\
\hline Other & $16(5)$ & $13(5)$ & $3(4)$ & \\
\hline \multicolumn{5}{|l|}{ Employed in social/health care $\mathrm{n}(\%)$} \\
\hline Yes & $81(26)$ & $66(27)$ & $15(21)$ & \\
\hline No & $233(74)$ & $177(73)$ & $56(79)$ & \\
\hline \multicolumn{5}{|l|}{ Earlier arthroplasty n (\%) } \\
\hline First arthroplasty & $244(76)$ & $188(76)$ & $56(77)$ & \\
\hline Second or more arthroplasty & $76(24)$ & $59(24)$ & $17(23)$ & \\
\hline \multicolumn{5}{|l|}{ Hospital stay as expected $\mathrm{n}(\%)$} \\
\hline Yes & $282(91)$ & $216(90)$ & $66(93)$ & \\
\hline Hospital stay in days Mean $( \pm \mathrm{SD})$ & $6(5)$ & $6(5)$ & $6(2)$ & \\
\hline
\end{tabular}

${ }^{\mathrm{a} C h i-2 ~ t e s t ~}$ 


\section{Table 2}

Mean differences between received and expected knowledge and number of patients with unfulfilled knowledge expectation

\begin{tabular}{|c|c|c|c|c|c|}
\hline Dimensions & $\begin{array}{c}\text { Received } \\
\text { knowledge }^{\mathrm{a}} \\
\text { Mean }( \pm \mathrm{SD})\end{array}$ & $\begin{array}{c}\text { Expected } \\
\text { knowledge }^{\mathrm{a}} \\
\text { Mean }( \pm \mathrm{SD})\end{array}$ & $\begin{array}{c}\text { Mean } \\
\text { difference } \\
\text { Mean ( } \pm \text { SD) }\end{array}$ & $p^{\mathbf{b}}$ & $\begin{array}{c}\text { Number of patients } \\
\text { with unfulfilled } \\
\text { expectations } \\
\text { n (\%) }\end{array}$ \\
\hline Bio-Physiological & $3.5(0.5)$ & $3.8(0.3)$ & $-0.3(0.6)$ & $<0.001$ & $173(55 \%)$ \\
\hline Functional & $3.5(0.5)$ & $3.8(0.4)$ & $-0.3(0.6)$ & $<0.001$ & $181(57 \%)$ \\
\hline Experiential & $2.7(0.1)$ & $3.5(0.7)$ & $-0.8(1.1)$ & $<0.001$ & $183(64 \%)$ \\
\hline Ethical & $2.8(0.9)$ & $3.5(0.6)$ & $-0.7(1.0)$ & $<0.001$ & $222(71 \%)$ \\
\hline Social & $2.6(1.0)$ & $3.4(0.6)$ & $-0.8(1.0)$ & $<0.001$ & $214(70 \%)$ \\
\hline Financial & $2.2(1.0)$ & $3.5(0.7)$ & $-1.3(1.2)$ & $<0.001$ & $227(81 \%)$ \\
\hline Total scale & $3.0(0.7)$ & $3.6(0.4)$ & $-0.6(0.8)$ & $<0.001$ & $247(77 \%)$ \\
\hline
\end{tabular}

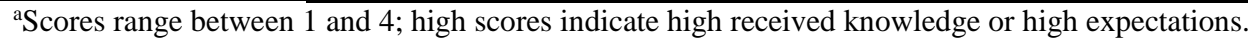

${ }^{\mathrm{b}} p$-value from paired sample t-test (received - expected knowledge) 


\section{Table 3}

Symptoms and emotions before hospital admission and correlation with the differences between received and expected knowledge $(n=320)$

\begin{tabular}{lccc}
\hline & $\begin{array}{c}\text { Prevalence }^{\mathbf{a}} \\
\mathbf{n}(\%)\end{array}$ & $\begin{array}{c}\text { Distribution }^{\mathbf{b}} \\
\text { Md }(\mathbf{Q 1}, \mathbf{Q 3})\end{array}$ & $\begin{array}{c}\text { Correlation }^{\text {coefficient }^{\mathbf{c}}} \\
\mathbf{r s}_{\mathbf{s}}\end{array}$ \\
\hline $\begin{array}{l}\text { Symptoms } \\
\text { pain }\end{array}$ & $317(100)$ & $4(3,4)$ & $-.162^{* *}$ \\
$\quad$ tiredness or fatigue & $284(88)$ & $3(2,3)$ & $-.180^{* *}$ \\
sleeplessness & $242(77)$ & $3(2,3)$ & $-.157^{* *}$ \\
sense of weakness & $239(77)$ & $2(2,3)$ & $-.265^{* *}$ \\
itching & $101(33)$ & $1(1,2)$ & -.102 \\
breathlessness & $95(31)$ & $1(1,2)$ & .004 \\
loss of appetite & $90(29)$ & $1(1,2)$ & -.082 \\
nausea or vomiting & $58(19)$ & $1(1,1)$ & $-.139 *$ \\
Emotions & & & -.064 \\
hope & $299(96)$ & $4(3,4)$ & $-.277^{* *}$ \\
concern & $267(85)$ & $2(2,3)$ & $-.240^{* *}$ \\
impatience & $237(76)$ & $2(2,3)$ & $-.269^{* *}$ \\
uncertainty & $226(73)$ & $2(1,2)$ & $-.331^{* *}$ \\
fear & $205(66)$ & $2(1,3)$ & $-.243^{* *}$ \\
anxiety & $183(59)$ & $2(1,3)$ & $-.328^{* *}$ \\
depressive state & $170(55)$ & $2(1,2)$ & $-.247^{* *}$ \\
despair or hopelessness & $139(45)$ & $1(1,2)$ & $-.267^{* *}$ \\
grief & $136(44)$ & $1(1,2)$ & \\
\hline Score $\geq 2$ & & &
\end{tabular}

${ }^{\text {a Score }} \geq 2$
bScores range between 1 and 4, 1= not at all, 2= rarely, $3=$ sometimes, $4=$ very often

${ }^{\mathrm{c}}$ Differences between received and expected knowledge range from -2.95 to 2.27

$* p<0.05, * * p<0.01$ 
Table 4. Variables predicting for the difference between received and expected knowledge

\begin{tabular}{lccccc}
\hline Variable & $\boldsymbol{B}$ & S.E. & Beta & $\boldsymbol{t}$-value & $\boldsymbol{p}$-value \\
\hline Depressive state $^{\mathrm{a}}$ & -.234 & .064 & -.260 & -3.673 & $<.001$ \\
Professional education $^{\mathbf{b}}$ & -.108 & .039 & -.156 & -2.773 & .006 \\
Country $^{\mathbf{c}}$ & .173 & .057 & .188 & 3.031 & .003 \\
Anxiety $^{\mathbf{a}}$ & -.143 & .057 & -.168 & -2.524 & .012 \\
Constant & -.715 & .392 & & -1.882 & .070 \\
\hline$R^{2}=234$, &
\end{tabular}

$R^{2}=.234$, adjusted $R^{2}=.221, F=18.688 \mathrm{df}(4,245), p=<0.001$

${ }^{\mathrm{a}} 1=$ not at all $2=$ rarely, $3=$ sometimes, $4=$ very often

b $1=$ none $2=$ Secondary level, $3=$ College level, $4=$ academic level

c $1=$ Sweden, $2=$ Finland, $3=$ Iceland 